\title{
DETERMINAÇÃO DIRETA DE CRÔMIO EM AÇÚCAR E LEITE POR ESPECTROMETRIA DE ABSORÇÃO ATÔMICA COM ATOMIZAÇÃO ELETROTÉRMICA EM FORNO DE GRAFITE
}

Sueli P. Quináia e Joaquim A Nóbrega*

Departamento de Química - Centro de Ciências Exatas e de Tecnologia - Universidade Federal de São Carlos - CP 676 13565-970 - São Carlos - SP

Recebido em 26/1/99; aceito em 26/7/99

\begin{abstract}
DIRECT DETERMINATION OF CHROMIUM IN SUGAR AND MILK USING GRAPHITE FURNACE ATOMIC ABSORPTION SPECTROMETRY. A fast and direct method for the determination of $\mathrm{Cr}$ in milk and cane sugar suspensions using graphite furnace atomic absorption spectrometry with Zeeman-effect background correction is described. No sample pre-treatment was necessary, minimizing the risk of contamination. The concentration of chromium in cane sugar was evaluated using $\mathrm{Cr}$ reference solutions prepared in $1 \% \mathrm{v} / \mathrm{v} \mathrm{HNO}_{3}$ solution. The milk samples were introduced into the furnace with a mixture of amines for avoiding the autosampler blockage and foaming of milk. Chromium determination in milk was based on the standard additions method (SAM). The limit of detection and characteristic mass for cane sugar sample $(30 \mu \mathrm{L})$ were $0,13 \mathrm{ng} /$ $\mathrm{ml}$ and $4,3 \mathrm{pg}$, and for milk sample $(10 \mu \mathrm{L})$ were $0,23 \mathrm{ng} / \mathrm{ml}$ and $7,8 \mathrm{pg}$, respectively. The graphite tube lifetime was 300 firings for sugar-cane sample and 100 firings for milk sample. The heating program was implemented in $68 \mathrm{~s}$.
\end{abstract}

Keywords: milk; sugar-cane; chromium; graphite furnace; electrothermal atomization.

\section{INTRODUÇÃO}

A determinação de baixas concentrações de $\mathrm{Cr}$ é relevante considerando-se os efeitos fisiológicos desse elemento. $\mathrm{O} \mathrm{Cr}$ possui papel importante no metabolismo da glicose, formando um complexo com moléculas de ácido nicotínico que auxiliam os processos de degradação do açúcar no sangue pela ação da insulina. Por outro lado, concentrações elevadas são letais, principalmente do metal na forma mais oxidada ${ }^{1}$.

A determinação de $\mathrm{Cr}$ em matrizes complexas ainda é um desafio analítico criticamente afetado por contaminação durante processos de preparo de amostras, que podem causar elevados sinais para o branco analítico ${ }^{2}$.

A cana contém $73-76 \%$ de água e $24-27 \%$ de sólidos, sendo que $10-17 \%$ são sólidos solúveis e 11-16 \% são fibras. Considerando a baixa concentração de $\mathrm{Cr}$ e a complexidade do açúcar, que é essencialmente composto por material orgânico, como glicose $(2-4 \%)$, sacarose $(70-88 \%)$, frutose $(2-4 \%)$, sais de ácidos inorgânicos e orgânicos, proteínas, amido, goma, ceras e gorduras, a determinação de $\mathrm{Cr}$ nessa matriz não é trivial. Os principais aminoácidos encontrados na cana são ácido aspartático e glutâmico e os principais sais inorgânicos são cloretos e sulfatos de potássio, cálcio e magnésio ${ }^{3}$.

O conteúdo de metais em cana de açúcar é variável e dependente da região de cultivo. Quanto maior for o número de processos envolvidos no tratamento para refino, menor será a quantidade de metais encontrados no açúcar ${ }^{4}$. O processo de refino do açúcar de cana envolve três etapas de clarificação (fosfatação, talo-fosfatação e carbonação) seguidas por procedimentos combinados com resinas de troca iônica e carvão ativo $^{3}$. Dessa forma, o refinamento do açúcar geralmente causa completa eliminação do $\mathrm{Cr}^{4}$. Assim, maiores teores de $\mathrm{Cr}$ devem ser encontrados no açúcar mascavo e em derivados desse, como por exemplo a rapadura. Na legislação brasileira, segundo o Decreto $55871^{5}$, o teor máximo permissível de $\mathrm{Cr}$ em alimentos é de $0,1 \mathrm{mg} / \mathrm{kg}$ no produto pronto para consumo.

A composição do leite é determinante para o estabelecimento da sua qualidade nutricional e adequação para processamento e consumo humano. Estima-se que o leite possua em torno de cem mil constituintes distintos, embora a maioria deles não tenha ainda sido identificada. O leite é constituído principalmente por água $(873 \mathrm{~g} / \mathrm{kg})$, lactose $(46 \mathrm{~g} / \mathrm{kg})$, gordura $(39 \mathrm{~g} /$ $\mathrm{kg}$ ), proteínas $(32,5 \mathrm{~g} / \mathrm{kg})$, substâncias minerais $(6,5 \mathrm{~g} / \mathrm{kg})$ e ácidos orgânicos $(1,8 \mathrm{~g} / \mathrm{kg})^{6,7}$.

A espectrometria de absorção atômica (AAS) é uma das técnicas mais utilizadas para a determinação de metais em materiais biológicos. Entre os trabalhos encontrados na literatura sobre determinação de metais em açúcar, a maioria utiliza AAS, preferencialmente com atomização eletrotérmica em forno de grafite. Miller-Ihli e Greene ${ }^{8}$ utilizaram solução de $\mathrm{HNO}_{3} \quad 5 \%$ v/v para a determinação de chumbo em açúcar. Uma solução de nitrato de magnésio $2 \% \mathrm{~m} / \mathrm{v}$ foi utilizada como modificador químico. Em outro estudo Miller-Ihli ${ }^{9}$ determinou chumbo em açúcares e xaropes através do método de digestão via úmida com $\mathrm{HNO}_{3} 50 \%$ v/v e $\mathrm{H}_{2} \mathrm{O}_{2}$ em uma temperatura de $90^{\circ} \mathrm{C}$. Stein e Umland ${ }^{10}$ determinaram $\mathrm{Pb}^{2+}, \mathrm{Cd}^{2+}$ e $\mathrm{Mg}^{2+}$ em amostras de mel e açúcar. Compararam três métodos de preparação de amostras: dissolução direta em $\mathrm{HNO}_{3}$ 0,01 mol/L, extração com dietilditiocarbamato e método de decomposição de amostra com $\mathrm{H}_{2} \mathrm{SO}_{4} / \mathrm{H}_{2} \mathrm{O}_{2}$. O método direto de dissolução das amostras apresentou a melhor repetibilidade. Em todos esses trabalhos a técnica de forno de grafite foi utilizada. Já Veres e Strurcz ${ }^{11}$ avaliaram os efeitos causados pela matriz durante a determinação de $\mathrm{Cu}^{2+}, \mathrm{Zn}^{2+}, \mathrm{Fe}^{3+}, \mathrm{Cr}^{3+}$ e $\mathrm{Cr}_{2} \mathrm{O}_{7}^{2-}$ em açúcar por espectrometria de absorção atômica com chama (FAAS). Estudaram o efeito do $\mathrm{pH}$, vazão dos gases ar-acetileno e altura de observação na chama. Lima et al ${ }^{12}$ desenvolveram um método direto para a determinação de $\mathrm{Pb}^{2+} \mathrm{em}$ sucos de frutas, xaropes e mel sem procedimento de digestão das amostras por atomização eletrotérmica em forno de grafite. As amostras foram dissolvidas em água, acidificadas com $\mathrm{HNO}_{3} \quad 0,2 \% \mathrm{v} / \mathrm{v}$ e injetadas diretamente em um forno de grafite totalmente pirolítico com aquecimento transversal. Utilizaram a mistura de $5 \mu \mathrm{g} \mathrm{Pd}+3 \mu \mathrm{g} \mathrm{Mg}\left(\mathrm{NO}_{3}\right)_{2}$ como modificador químico, o que possibilitou o emprego de uma temperatura de pirólise de $1000^{\circ} \mathrm{C}$, e a duração do ciclo de aquecimento para cada medida foi de $105 \mathrm{~s}$.

Atenção considerável tem sido dada para a determinação 
de $\mathrm{Cr}$ em leite. Kumpulainen ${ }^{13}$, Emmett $^{14}$ e Viñas et al ${ }^{15}$ determinaram a concentração de $\mathrm{Cr}$ em leite utilizando as técnicas de atomização eletrotérmica em forno de grafite e espectrometria de massa com plasma acoplado, nos três artigos citados, todos usaram métodos de digestão ácida para posterior determinação do $\mathrm{Cr}$. Mingorance e Lachica ${ }^{16}$ determinaram $\mathrm{Cr}$ em leite sem digestão da amostra, apenas adicionaram álcool noctil no meio para evitar a formação de bolhas durante o procedimento de amostragem no tubo de grafite. Utilizaram uma lâmpada de $\mathrm{D}_{2}$ como corretor de fundo que apresenta baixa intensidade de emisão no comprimento de onda utilizado para determinação de $\mathrm{Cr}(357,9 \mathrm{~nm})$. Minoia e $\operatorname{Caroli}^{17}$ fizeram determinação direta de vários elementos essenciais em leite utilizando atomização eletrotérmica em forno de grafite com corretor Zeeman. Para a determinação de $\mathrm{Cr}$ misturaram $0,9 \mathrm{ml}$ de leite e $0,1 \mathrm{ml}$ de modificador químico $\mathrm{Mg}\left(\mathrm{NO}_{3}\right)_{2}$, a suspensão foi agitada e um volume de $20 \mu \mathrm{l}$ foi introduzido no tubo de grafite. Lameiras et al. ${ }^{18}$ quantificaram o teor de $\mathrm{Cr}$ (VI) e $\mathrm{Cr}$ total em leite por atomização eletrotérmica em forno de grafite. $\mathrm{O} \mathrm{Cr}$ total foi determinado em leite através da adição de Triton X-100 e uma mistura de Pd e Mg utilizado como modificador químico. Para a separação do $\mathrm{Cr}$ hexavalente utilizouse procedimento de precipitação das proteínas e posterior eluição do sobrenadante com ácido nítrico. O comprimento de onda utilizado foi o alternativo de $353,7 \mathrm{~nm}$, o corretor de fundo foi a lâmpada de deutério e a duração do programa de aquecimento foi de $134 \mathrm{~s}$.

Neste trabalho foi desenvolvido um método para a determinação direta de $\mathrm{Cr}$ em amostras de açúcar e derivados provenientes de diferentes regiões do Brasil e amostras de leite em pó e em líquido contidas em diferentes embalagens.

\section{MATERIAIS E MÉTODOS}

\section{Instrumentação}

As determinações de $\mathrm{Cr}$ foram feitas em um espectrômetro de absorção atômica com atomização eletrotérmica em forno de grafite GTA 100 (Varian, modelo 800), equipado com corretor Zeeman para correção de fundo, amostrador automático, sistema de aquisição de dados OS 2 , lâmpada de catodo oco de $\mathrm{Cr}$, operando a $7 \mathrm{~mA}$ no comprimento de onda de $357,9 \mathrm{~nm}$ (fenda de $0,2 \mathrm{~nm})$. Foram empregados tubos de grafite recobertos piroliticamente (Part number 63-100011-00) e Ar 4.8 (White Martins) como gás de purga. Utilizou-se integração dos sinais para eliminar erros na leitura de sinais causados por efeitos cinéticos que possam ocorrer durante o ciclo de aquecimento. $\mathrm{O}$ programa de aquecimento é apresentado na Tabela 1. Os volumes injetados no forno de grafite foram de $30 \mu \mathrm{L}$ para as suspensões de açúcar e $10 \mu \mathrm{L}$ para as amostras de leite. Os copos do amostrador automático foram previamente descontaminados ${ }^{19}$.

Tabela 1. Programa de Aquecimento proposto para determinação de $\mathrm{Cr}$.

\begin{tabular}{ccccc}
\hline Etapa & T $\left({ }^{\circ} \mathrm{C}\right)$ & Tempo $(\mathrm{s})$ & $\begin{array}{c}\text { Fluxo gás } \\
(\mathrm{L} / \mathrm{min})\end{array}$ & Leitura \\
\hline 1 & 85 & 5 & 3 & Não \\
2 & 95 & 40 & 3 & Não \\
3 & 120 & 10 & 3 & Não \\
4 & $*$ & 5 & 3 & Não \\
5 & $*$ & 1 & 3 & Não \\
6 & $*$ & 2 & 0 & Não \\
7 & 2400 & 1,2 & 0 & Sim \\
8 & 2400 & 2 & 0 & Sim \\
9 & 2500 & 2 & 3 & Não \\
\hline
\end{tabular}

- * $400^{\circ} \mathrm{C}$ para açúcar

- $* 1600^{\circ} \mathrm{C}$ para leite

\section{Reagentes e Soluções}

Todos os reagentes utilizados neste estudo foram de grau analítico; água destilada-deionizada (Milli-Q) foi usada em todos os experimentos.

Solução estoque de $1000 \mathrm{mg} / \mathrm{ml}$ foi preparada a partir de $\mathrm{Cr}$ metálico (Aldrich Chem. Co., USA): 1,000 g de Cr metálico foi dissolvido em $\mathrm{HCl}$ 1:1 v/v sob aquecimento, e a solução obtida foi diluída em água.

Os experimentos foram conduzidos com soluções de referência contendo de 2 a $6 \mathrm{mg} / \mathrm{L}$ de $\mathrm{Cr}$ em meio $1,0 \% \mathrm{v} / \mathrm{v}$ de $\mathrm{HNO}_{3}$.

Foi usada uma mistura de aminas terciárias (CFAC, Spectrasol, USA) concentrada. A composição dessa mistura não é conhecida e uma discussão sobre suas aplicações pode ser encontrada na referência ${ }^{20}$. Para a determinação de $\mathrm{Cr}$ em leite utilizou-se $0,5 \mathrm{~mL}$ de amina concentrada para 9,5 $\mathrm{mL}$ de leite.

Utilizou-se uma solução de1500 mg/L de $\mathrm{Mg}\left(\mathrm{NO}_{3}\right)_{2}$.

\section{Amostras}

Amostras de rapadura, açúcar mascavo, açúcar cristal, açúcar refinado e leite foram adquiridas no comércio. Visou-se avaliar o teor de $\mathrm{Cr}$ em açúcares e derivados provenientes de diferentes localidades. Foi determinado o teor de $\mathrm{Cr}$ em amostras de leite contidas em embalagens plásticas, em caixas de papel revestidas com alumínio e em lata de alumínio.

\section{PARTE EXPERIMENTAL}

\section{Desenvolvimento de método para a determinação de $\mathrm{Cr}$ em açúcar}

\section{Dissolução de amostra e atomização de Cr: efeito de pH}

Foram pesadas massas de aproximadamente $1 \mathrm{~g}$ de açúcar e adicionadas em dois meios diferentes: $1 \% \mathrm{v} / \mathrm{v} \mathrm{HNO}_{3}$ e água deionizada. O açúcar foi completamente dissolvido nos dois meios após 5 min de agitação. Completou-se o volume para 50 $\mathrm{ml}$ em cada meio. Um volume de $30 \mu \mathrm{l}$ de amostra foi introduzido no tubo de grafite.

\section{Programa de aquecimento: curvas de temperatura de pirólise}

Para o estabelecimento da máxima temperatura de pirólise sem perdas de $\mathrm{Cr}$ por volatilização, curvas de temperatura de pirólise foram experimentalmente obtidas em meio $1 \% \mathrm{v} / \mathrm{v}$ $\mathrm{HNO}_{3}$ e água deionizada. Adicionaram-se $10 \mathrm{mg}$ de $\mathrm{Cr} / \mathrm{L} \mathrm{em}$ cada meio. As curvas foram geradas pela variação de temperatura de 200 a $1800^{\circ} \mathrm{C}$ fixando-se a temperatura de atomização em $2400^{\circ} \mathrm{C}$. O programa de aquecimento sem a etapa de pirólise também foi avaliado.

\section{Determinação de Cr em açúcar}

Para averiguar efeitos de matriz, dois procedimentos de quantificação foram utilizados: o primeiro envolveu soluções de referência preparadas em $1 \% \mathrm{v} / \mathrm{v} \mathrm{HNO}_{3}$ e o outro adotando o método das adições de padrão.

Para o desenvolvimento desse método, 7 amostras de açúcar foram selecionadas para avaliar o efeito da variação de matriz. Diferentes marcas de açúcar foram empregadas. Aproximadamente $1 \mathrm{~g}$ de cada amostra foi pesado e as amostras foram dissolvidas em $25 \mathrm{ml}$ de água deionizada. As amostras foram preparadas em triplicata.

Para avaliar a exatidão utilizou-se o método de adição e recuperação de $\mathrm{Cr}$ nas amostras. 
Desenvolvimento de método para a determinação de $\mathrm{Cr}$ em leite

\section{Diluição da amostra: efeito de viscosidade}

Adicionaram-se teores conhecidos de $\mathrm{Cr}$ em amostras de leite integral, semi-desnatado e desnatado. As amostras foram preparadas em diferentes meios de diluição: $5 \mathrm{ml}$ de leite +5 $\mathrm{ml}$ de água; 9,9 $\mathrm{ml}$ de leite $+0,1 \mathrm{ml}$ de mistura de aminas terciárias; $9,5 \mathrm{ml}$ de leite $+0,5 \mathrm{ml}$ de mistura de aminas terciárias e leite + modificador químico $(\mathrm{Mg})$. Para este estudo foram utilizadas as seguintes temperaturas de pirólise e de atomização: $1300^{\circ} \mathrm{C}$ e $2400^{\circ} \mathrm{C}$, respectivamente.

\section{Programa de aquecimento: curvas de temperatura de pirólise}

Curvas de temperatura de pirólise foram feitas com o leite integral, com leite integral + modificador químico $(1500 \mu \mathrm{g} / \mathrm{ml}$ de $\mathrm{Mg})$ e com leite integral + aminas terciárias $(5 \% \mathrm{v} / \mathrm{v})$

Um estudo do efeito da duração do tempo de pirólise foi realizado para amostras de leite integral. Curvas de sinal de absorção atômica versus tempo de pirólise foram obtidas para amostras de leite com modificador $(\mathrm{Mg})$ e leite com amina 5\% $\mathrm{v} / \mathrm{v}$. Adicionaram-se $10 \mathrm{ng} \mathrm{Cr} \mathrm{ml}{ }^{-1} \mathrm{em}$ todas as amostras.

\section{Determinação de Cr em leite}

Devido aos efeitos causados pela matriz, o procedimento de quantificação utilizado envolveu o método das adições de padrão. Adicionou-se $0,5 \mathrm{ml}$ de aminas terciárias concentrada a 9,5 $\mathrm{ml}$ de leite. Para a determinação de $\mathrm{Cr}$ em leite em pó pesaram-se aproximadamente $5 \mathrm{~g}$ de leite em pó e adicionaram-se em $30 \mathrm{ml}$ de água. As amostras foram preparadas em triplicata.

Para avaliar a exatidão do método utilizou-se material de referência certificado (A-11, Agência Internacional de Energia Atômica - AIEA, Austria).

\section{RESULTADOS E DISCUSSÃO}

\section{Açúcar}

A Figura 1 contém os sinais de absorção atômica (AA) e de fundo (BG) obtidos para $\mathrm{Cr}$ em açúcar nos meios avaliados. Os sinais gerados têm perfis semelhantes o que indica que o processo de atomização é similar em ambos os meios. No entanto, o sinal atômico obtido para o $\mathrm{Cr}$ em meio $1 \% \mathrm{v} / \mathrm{v} \mathrm{HNO}_{3}$ aparece alguns segundos antes do sinal obtido para $\mathrm{Cr}$ em água pois as temperaturas de pirólise são diferentes. As curvas de temperatura de pirólise obtidas para uma amostra de açúcar mascavo nos dois meios de suspensão estão apresentadas na Figura 2. Verificou-se que a máxima temperatura de pirólise obtida sem perda de $\mathrm{Cr}$ por volatilização foi de $1600^{\circ} \mathrm{C}$ para a amostra suspensa em água e $1500^{\circ} \mathrm{C}$ para a amostra suspensa em meio $\mathrm{HNO}_{3}$. Acima dessas temperaturas o $\mathrm{Cr}$ foi volatilizado. Esse comportamento é esperado mesmo na ausência de modificadores químicos devido ao caráter refratário do $\mathrm{Cr}$ e à possibilidade de formação de carbetos. Apesar da introdução direta da amostra complexa no tubo de grafite, o sinal de fundo foi baixo, conforme pode ser visto na Figura 2. Para uma temperatura de pirólise de $200^{\circ} \mathrm{C}$, o sinal de fundo foi de 0,230 ; enquanto que a partir de $400^{\circ} \mathrm{C}$ o sinal decresceu para 0,025 permanecendo nesse patamar para as demais temperaturas de pirólise estudadas. Observou-se que na temperatura de $1500^{\circ} \mathrm{C}$ a sensibilidade alcançada para o meio ácido foi maior que no meio utilizando apenas água. No entanto, preferiu-se utilizar a suspensão preparada em água na temperatura de pirólise de $400^{\circ} \mathrm{C}$, pois a mesma apresenta baixo sinal de fundo e, nesse caso, a vida útil do tubo de grafite seria maior. Observou-se que o sinal de fundo obtido sem o uso de uma etapa de pirólise foi de 0,640.

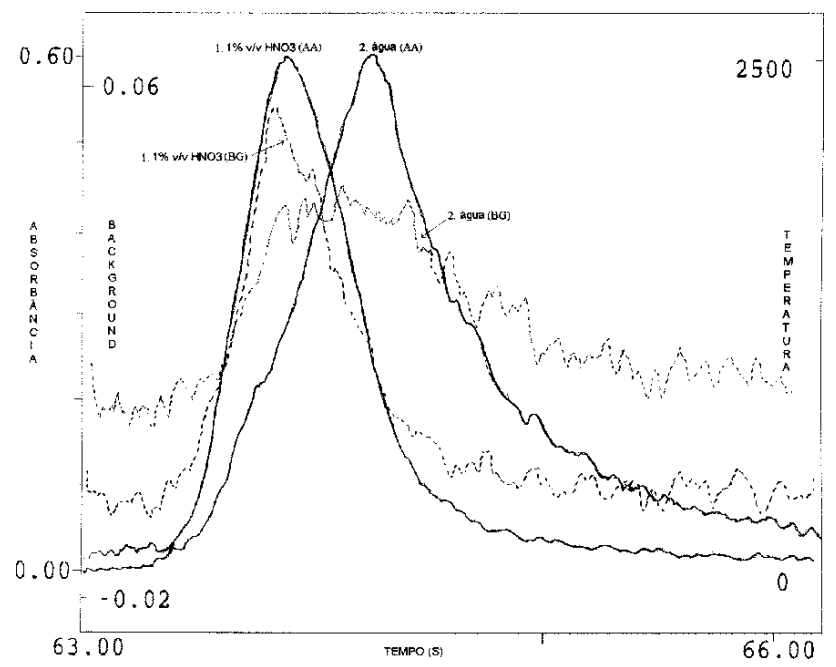

Figura 1. Sinais de absorção atômica e de fundo para Cr em açúcar em diferentes meios: 1) em meio $1 \% \mathrm{v} / \mathrm{v} \mathrm{HNO}_{3}$, temperatura de pirólise: $1500^{\circ} \mathrm{C}$ e 2) em água, temperatura de pirólise: $1600^{\circ} \mathrm{C}$. Temperatura de atomização: $2400^{\circ} \mathrm{C}$.

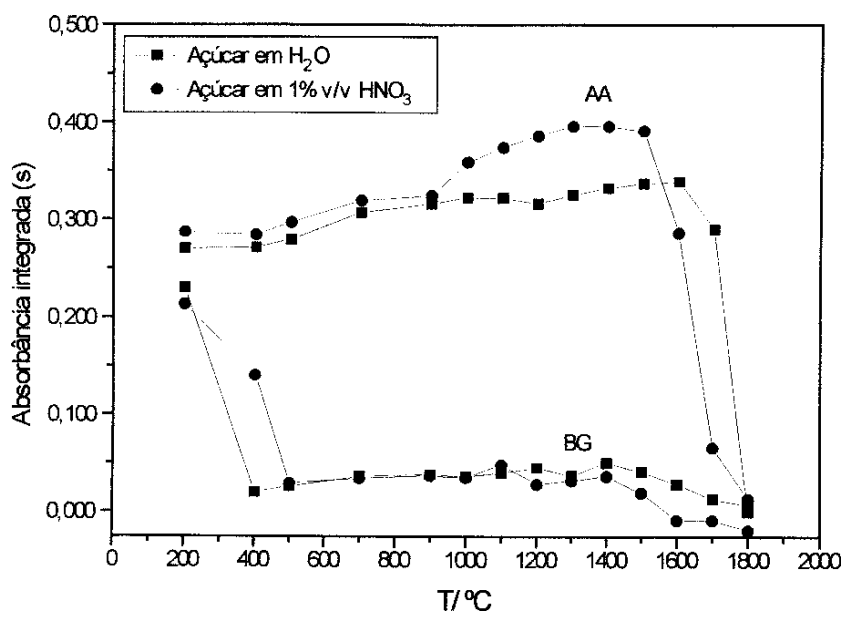

Figura 2. Curvas de temperatura de pirólise para $\mathrm{Cr}$ em açúcar com medidas de absorção atômica $(A A)$ e sinal de fundo $(B G)$. Temperatura de atomização: $2400^{\circ} \mathrm{C}$.

A Figura 3 representa os sinais de absorção atômica e de fundo para a suspensão do açúcar em água em diferentes temperaturas de pirólise. Os sinais indicam a ocorrência de uma separação temporal entre AA e BG na temperatura de pirólise de $200^{\circ} \mathrm{C}$ e também quando a etapa de pirólise foi excluída do programa de aquecimento. Neste último caso, observou-se que a vida útil do tubo de grafite foi $50 \%$ menor.

Depois de estabelecido o procedimento para dissolução das amostras de açúcar e as condições para atomização do $\mathrm{Cr}$ em forno de grafite, o próximo passo foi avaliar o procedimento que deveria ser utilizado para a quantificação de $\mathrm{Cr}$ nas amostras. Dois procedimentos foram investigados: soluções de referência de $\mathrm{Cr}$ preparadas em meio $1 \% \mathrm{v} / \mathrm{v} \mathrm{HNO}_{3}$ e o método das adições de padrão. $\mathrm{O}$ estudo foi realizado com duas amostras de açúcar mascavo, sendo uma delas mais escura e a outra mais clara. A atomização de $\mathrm{Cr}$ foi igual para os dois procedimentos avaliados. Para a amostra de açúcar mascavo escuro foram obtidos os valores de $2,66 \mathrm{ng} \mathrm{Cr} / \mathrm{ml}$ (método das adições de padrão) e 2,67 ng $\mathrm{Cr} / \mathrm{ml}$ (curva de calibração com soluções de referência), para a amostra de açúcar mascavo claro foram obtidos os valores de $0,28 \mathrm{ng} \mathrm{Cr} / \mathrm{ml}$ (método das adições de padrão) e $0,32 \mathrm{ng} \mathrm{Cr} / \mathrm{ml}$ (curva de calibração com soluções de referência). As inclinações obtidas com as curvas 

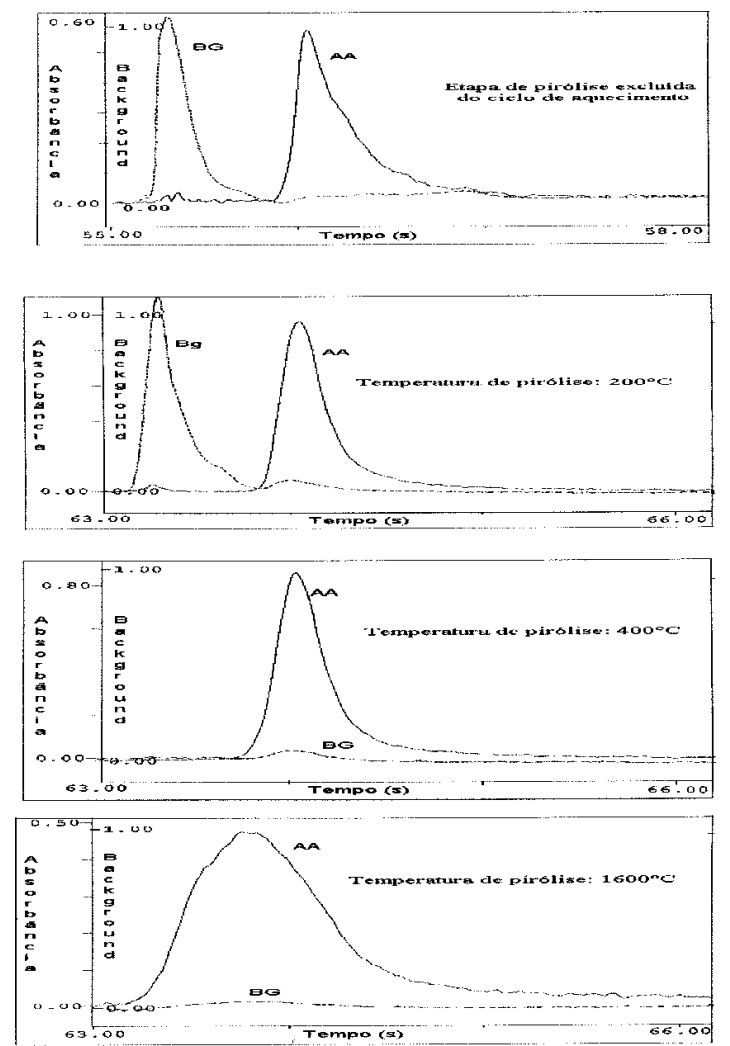

Figura 3. Sinais de absorção atômica $(A A)$ e de fundo $(B G)$ para diferentes temperaturas de pirólise. Temperatura de atomização: $2400^{\circ} \mathrm{C}$.

foram 0,041 e 0,040 para $\mathrm{Cr}$ em $\mathrm{HNO}_{3}$ e para açúcar em água, respectivamente. Isso demonstra que não há necessidade do uso do método das adições de padrão.

Os resultados obtidos empregando-se soluções de referência estão apresentados na Tabela 2. Foram detectados maiores teores de $\mathrm{Cr}$ nas amostras de açúcar não refinadas. A maior concentração de $\mathrm{Cr}$ foi obtida no açúcar mascavo escuro, depois na amostra de rapadura e por último no açúcar mascavo claro. Amostras de açúcar cristal e refinado não apresentaram $\mathrm{Cr}$ dentro do limite de detecção obtido pelo procedimento proposto. Esses resultados estão concordantes com a literatura que indica perdas apreciáveis de $\mathrm{Cr}$ durante processos de refinamento de certos alimentos ${ }^{4,21,22}$.

Tabela 2. Determinação de Cr em açúcar $(n=3)$.

\begin{tabular}{lc}
\hline \multicolumn{1}{c}{ Amostra } & Média $(\mathrm{ng} / \mathrm{g})$ \\
\hline Mascavo claro (RJ) & $13,7 \pm 1,7$ \\
Mascavo claro(SP) & $21,1 \pm 3,4$ \\
Mascavo escuro(SP) & $65,6 \pm 4,3$ \\
Mascavo escuro(NE) & $115,1 \pm 9,5$ \\
Rapadura (SP) & $62,3 \pm 5,3$ \\
Cristal & $<3,2$ \\
Refinado & $<3,2$ \\
\hline
\end{tabular}

Um estudo de adição e recuperação foi realizado em amostras de açúcar com diferentes teores de Cr. A Tabela 3 apresenta os resultados obtidos. A taxa de recuperação para $\mathrm{Cr}$ adicionado nas amostras variou de 95,9 a 98,5\%.

\section{Leite}

Com relação à determinação de $\mathrm{Cr}$ em leite, quatro diferentes meios de diluição foram testados: diluição em água, em solução de aminas terciárias nas concentrações de 1 e $5 \%$ v/ $\mathrm{v}$ e com modificador químico $(\mathrm{Mg})$. As inclinações das retas obtidas com as curvas nos diferentes meios foram: $1,00 \times 10^{-2}$ s. $(\mathrm{ng} / \mathrm{mL})^{-1}$ para diluição em água, $9,80 \times 10^{-3} \mathrm{~s} .(\mathrm{ng} / \mathrm{mL})^{-1}$ para solução de aminas $1 \% \mathrm{v} / \mathrm{v}, 7,80 \times 10^{-3} \mathrm{~s} .(\mathrm{ng} / \mathrm{mL})^{-1}$ para solução de aminas $5 \% \mathrm{v} / \mathrm{v}$ e $1,20 \times 10^{-2} \mathrm{~s} .\left(\mathrm{ng} / \mathrm{mL}^{-1}\right.$ para o modificador. Os sinais obtidos utilizando o modificador químico foram maiores, independente da quantidade de gordura contida no leite (integral, semi-desnatado e desnatado). No entanto, o coeficiente de variação dos sinais obtidos com o uso do modificador químico foi elevado devido ao acúmulo de gordura na parede interna do capilar após algumas medidas; os coeficientes de variação das medidas foram de $15 \%$ com o uso de modificador e de $2 \%$ com o uso de mistura de aminas. Provavelmente a função das aminas terciárias seria desestruturar a caseína do leite deixando o metal livre para ser atomizado ${ }^{23}$. Verificou-se que não há ganho de sensibilidade com a utilização da mistura de aminas terciárias, no entanto, a repetibilidade dos sinais é excelente quando comparado com o modificador químico. Outro fator considerado importante no uso das aminas é que não ocorre entupimento no capilar do amostrador automático com a gordura contida no leite. Outro benefício proveniente da mistura de aminas terciárias é que a gota formada dentro do tubo de grafite é mais perfeita, isto é, evita a formação de bolhas durante o procedimento de amostragem. A melhor repetibilidade dos sinais e o impedimento da formação de bolhas dentro do tubo de grafite foi obtido com uso de aminas na concentração de $5 \%$ v/v. Quanto maior for a concentração das aminas terciárias introduzidas nas amostras de leite, menor será a sensibilidade dos sinais analíticos gerados devido à elevada quantidade de carbono existente no meio. Teores elevados de carbono favorecem a formação de carbetos refratários que podem interferir nos processos de atomização do $\mathrm{Cr}$ e a formação de resíduos de carbono também pode ocluir o analito.

Como foi verificado através do estudo de preparo das amostras de leite, o modificador químico proporcionou sinais maiores. Devido a esse fato, procurou-se avaliar através de curvas de temperatura de pirólise qual o seu efeito sobre o comportamento térmico do elemento Cr. Pode ser observado na Figura 4 que o modificador aumentou a sensibilidade das medidas, mas não aumentou a estabilidade térmica do $\mathrm{Cr}$ na amostra.

Apesar do Mg aumentar os sinais atômicos, um problema que permanece no decorrer das medidas é o entupimento do capilar do amostrador e, consequentemente, a perda de repetibilidade dos volumes coletados pelo mesmo. Assim, optou-se pela utilização de amina $5 \% \mathrm{v} / \mathrm{v}$ para evitar esse tipo de problema, apesar da sensibilidade menor. Devido a isso, a repetibilidade dos sinais gerados é melhor do que quando se utilizou modificador químico ou diluição aquosa $1+1 \mathrm{v} / \mathrm{v}$. Com o estudo de curvas de temperatura de pirólise

Tabela 3. Adição e recuperação de $\mathrm{Cr}$ em açúcar.

\begin{tabular}{ccccc}
\hline Amostra & $\begin{array}{c}\text { Cr original } \\
(\mathrm{ng} / \mathrm{ml})\end{array}$ & $\begin{array}{c}\text { Cr adicionado } \\
(\mathrm{ng} / \mathrm{ml})\end{array}$ & $\begin{array}{c}\text { Cr encontrado (ng/ml) } \\
(\mathrm{ng} / \mathrm{ml})\end{array}$ & $\begin{array}{c}\text { Recuperação } \\
(\%)\end{array}$ \\
\hline Mascavo Claro & 0,86 & 0,60 & 1,40 & 95,9 \\
Rapadura & 0,86 & 1,30 & 2,11 & 97,7 \\
Mascavo escuro & 2,49 & 1,00 & 3,43 & 98,3 \\
& 4,15 & 0,60 & 4,68 & 98,5 \\
\hline
\end{tabular}




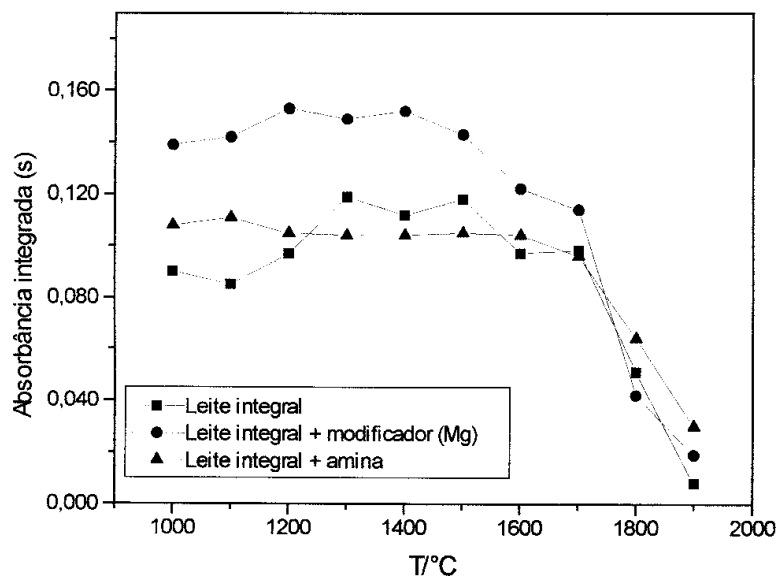

Figura 4. Curvas de temperatura de pirólise para $\mathrm{Cr}$ em amostras de leite integral. Temperatura de atomização: $2400^{\circ} \mathrm{C}$.

efetuado para o meio contendo amina $5 \% \mathrm{v} / \mathrm{v}$ e o meio contendo modificador químico $\mathrm{Mg}$, observou-se que a amina não interfere na temperatura ótima de pirólise (Figura 4). A partir desse estudo adotou-se a temperatura de pirólise de $1600^{\circ} \mathrm{C}$, pois nessa temperatura ainda não ocorria a volatilização do $\mathrm{Cr}$.

Com o estudo da variação do tempo utilizado na etapa de pirólise $\left(1600^{\circ} \mathrm{C}\right)$, que foi de 6 a $35 \mathrm{~s}$, foi possível verificar que o aumento da duração da etapa de pirólise não alterou os sinais de absorção atômica gerados para o meio contendo o modificador químico. Nessa temperatura de pirólise o $\mathrm{Mg}$ atuou como modificador químico pois os resultados foram iguais durante o aumento da duração da etapa de pirólise. $\mathrm{O}$ contrário foi observado para o meio contendo a mistura de aminas, quanto maior a duração da etapa de pirólise menor a sensibilidade (Figura 5). Como a mistura de aminas terciárias não é um modificador químico e a temperatura de pirólise é elevada não é possível aumentar a duração da etapa de pirólise por mais de $8 \mathrm{~s}$.

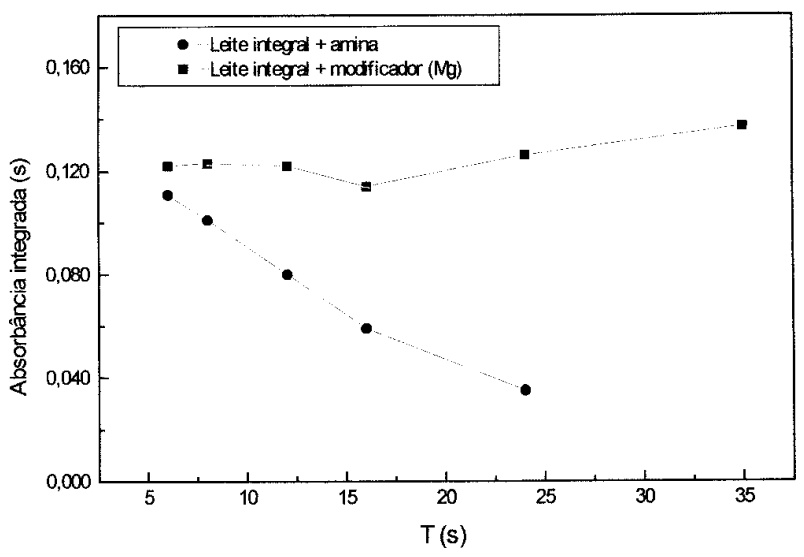

Figura 5. Estudo do tempo de duração para a etapa de pirólise em amostras de leite. Temperaturas de pirólise e de atomização: $1600^{\circ} \mathrm{C}$ e $2400^{\circ} \mathrm{C}$, respectivamente.

Como nos estudos anteriores observou-se maior sensibilidade com o uso de modificador químico e melhor repetibilidade dos sinais com o uso da mistura de aminas, avaliou-se o comportamento da atomização de $\mathrm{Cr}$ em leite utilizando-se a mistura de modificador químico com amina $5 \% \mathrm{v} / \mathrm{v}$. Os resultados não foram satisfatórios: a mistura de $\mathrm{Mg}$ com amina na determinação de $\mathrm{Cr}$ em leite apresentou menor sensibilidade.

$\mathrm{O}$ método desenvolvido para a determinação de $\mathrm{Cr}$ em leite foi aplicado à amostras de leite contidas em embalagens plásticas, em caixas de papel revestidas com alumínio e em lata de alumínio. O teor de $\mathrm{Cr}$ detectado nas amostras está apresentado na Tabela 4 . O método das adições de padrão foi utilizado em todas as medidas. Para validação do método proposto, utilizou-se material certificado de leite em pó. O teor de $\mathrm{Cr}$ discriminado pelo certificado foi de 17,7 $\mu \mathrm{g}$ de $\mathrm{Cr} / \mathrm{kg}$ com um intervalo de confiança entre 13,7 a $21,7 \mu \mathrm{g}$ de $\mathrm{Cr} / \mathrm{kg}$. O valor determinado de $\mathrm{Cr}$ no material certificado pelo método proposto para aproximadamente 0,5 e $1 \mathrm{~g}$ de leite foi de $21,2 \mathrm{e} 17,6 \mu \mathrm{g}$ de $\mathrm{Cr} / \mathrm{kg}$, respectivamente. O limite de detecção obtido na determinação de $\mathrm{Cr}$ em leite foi de $0,23 \mathrm{ng} / \mathrm{ml}$.

Tabela 4. Determinação de $\mathrm{Cr}$ em leite $(n=3)$

\begin{tabular}{cc}
\hline Tipo de leite /embalagem & $\mathrm{Cr}(\mathrm{ng} / \mathrm{g})$ \\
\hline Tipo C / plástica & $1,59 \pm 0,16$ \\
Pó / lata alumínio & $18,1 \pm 0,01$ \\
Integral /Caixa & $0,98 \pm 0,08$ \\
Pó/plástica* & $17,6 \pm 2,6$ \\
\hline
\end{tabular}

*Material certificado $(\mathrm{A} 11)=17,7 \mathrm{ng} / \mathrm{g}$ (intervalo de confiança: $13,7-21,7 \mathrm{ng} / \mathrm{g}$ )

O uso de aminas terciárias viabilizou a introdução direta da amostra de leite no forno de grafite sem causar perda de precisão e sem exigir etapas morosas de tratamento prévio, o que é crítico em termos de contaminação para o elemento Cr. Esse procedimento simples pode ser facilmente implementado para análises de rotina do elemento $\mathrm{Cr}$ em leite.

\section{AGRADECIMENTOS}

Os autores agradecem ao PADCT/CNPq, CAPES e CNPq o suporte financeiro recebido.

\section{REFERÊNCIAS}

1. Cimadevilla, E. A. C.; Wrobel, K.; Gayon, J. M. M.; SanzMedel, A.; J. Anal. At. Spectrom. 1994, 9, 117.

2. Taylor, A.; Branch, S.; Crews, H. M.; Halls, D. J.; White, M.; J. Anal. At. Spectrom. 1996, 11, 103R.

3. Ullmann's Encyclopedia of Industrial Chemistry, $\mathrm{VCH}$, Weinheim, 1989.

4. Adrian, J.; Sciences des Aliments 1991, 11, 417.

5. Ministério da Saúde, Diário Oficial da União, 23/01/1990, São Paulo, 1651-1654.

6. Silva, P. H. F.; Química Nova na Escola 1997, 6, 3.

7. Jensen, R. G.; Handbook of Milk Composition. Academic Press, London, 1995.

8. Miller-Ihli, N. J. Greene, F. E.; Atom. Spectrosc. 1993, $14,85$.

9. Miller-Ihli, N. J.; J AOAC Int. 1994, 77, 1288.

10. Stein, K.; Umland, F.; Fresenius Z Anal. Chem. 1986, 323,176

11. Veres, S., Strurcz, E. Magy-Kem-Foly 1997, 93, 199.

12. Lima, E. C.; Krug, F. J.; Arruda, M. A. Z.; Spectrochim. Acta B 1998, 53, 601 .

13. Kumpulainen, J.; Anal. Chim. Acta 1980, 113, 355.

14. Emmett, S. E.; J. Anal. At. Spectrom. 1988, 3, 1145.

15. Vinãs, P.; Campillo, N.; López-Garcia, I. e HernándezCórdoba, M.; Anal. Chim. Acta 1997, 356, 267.

16. Mingorance, M. D. e Lachica M.; Anal. Lett. 1985, 18 , 1519. 
17. Minoia, C. \& Caroli, S.; Applications of Zeeman Graphite Furnace atomic Absorption Spectrometry in the Chemical Laboratory and in Toxicology. Pergamon Press, 1992, 305.

18. Lameiras, J., Soares, M. E., Bastos, M. L, Ferreira, M.; Analyst 1998 123, 2091.

19. Barnes, R.M. ; Quináia, S. P.; Nóbrega, J. A.; Blanco, T.; Spectrochim. Acta B 1998, 53, 767.
20. WWW.Spectrasol.com

21. Sai, P. K. D.; Mohan, M. R.; Rao, S. B.; International Sugar Journal 1995, 97, 363.

22. Underwood, E. J.; Trace Elements in Human and Animal Nutrition. 4th, Academic Press, London, 1977.

23. Nóbrega, J. A.; Gélinas, Y., Krushevska, A.; Barnes, R. M.; J. Anal. At. Spectrom. 1997, 12, 1243. 